\title{
Observations on Rotating Instabilities and Spike Type Stall Inception in a High-Speed Multistage Compressor
}

\author{
Johannes Schreiber, Benoit Paoletti, and Xavier Ottavy \\ Laboratoire de Mécanique des Fluides et d'Acoustique, UMR CNRS 5509, Université de Lyon, Ecole Centrale de Lyon, UCB Lyon I, \\ INSA, 36 Av. Guy de Collongue, 69134 Écully Cedex, France
}

Correspondence should be addressed to Johannes Schreiber; johannes.schreiber@ec-lyon.fr

Received 17 March 2017; Revised 30 June 2017; Accepted 25 July 2017; Published 28 August 2017

Academic Editor: Feng Lin

Copyright (C) 2017 Johannes Schreiber et al. This is an open access article distributed under the Creative Commons Attribution License, which permits unrestricted use, distribution, and reproduction in any medium, provided the original work is properly cited.

\begin{abstract}
This work investigates high-frequency measurements for the contribution to the understanding of different stall inception types in high-speed multistage compressors. A 3.5-stage high-speed axial multistage compressor is investigated with a $2 \mathrm{MW}$ test rig in the Laboratoire de Mécanique des Fluides et d'Acoustique (LMFA) at Ecole Centrale de Lyon, France. Two different types of instabilities arise in this compressor as a function of shaft speed. At part speed, a controversy called "rotating instability" type flow field modulation is identified with the measurements. New results are the demonstration of the periodic behavior of this instability and the analogy to classical frequency modulation, periodic to one revolution of the instability. Furthermore, the amplitude of the instability is modulated by the time period of a rotor revolution. At nominal speed, the abrupt spike type stall inception is detected, taking usually less than five rotor revolutions.
\end{abstract}

\section{Introduction}

At the low mass flow rate end of the operating range, every axial compressor will ultimately experience rotating stall, one or several local rotating detached flow cell(s). This can be followed by surge, which is a system instability with a possible global flow reversal. There are two widely recognized rotating stall inception types for low- and highspeed axial compressors: modal and spike [1], though weak rotating perturbations can be present before the rotating stall inception, allowing a stable compression system operation. They are often reported as rotating instabilities in literature [2].

The need for detailed measurements in high-speed axial compressors and their analysis was clearly stated by Day [1] in 2015 reviewing 75 years of stall research and derived from flow features that can only be found in high-speed compressors. That environment poses a challenge in terms of measurement cost and technique but here the measurements are necessary to understand the instabilities arising in a real aircraft engine compressor. Numerical studies can be used for complementary flow field understanding but their limitations (particularly induced by the use of RANS modeling) need to be considered.

The spike stall inception describes an onset mechanism starting from a local strong perturbation of the flow field in the tip region of a rotor. Recent numerical and experimental works converge towards explaining the typical increase and decrease in wall pressure by a vortex structure forming at the leading edge of the rotor blade and spanning to the casing ("tornado vortex"). Inoue et al. [3] identified this numerically at first, and recent numerical and experimental works by Pullan et al. [4] support those results. In high-speed compressors, the spike type structure evolves very quickly (a few rotor revolutions) into a rotating stall cell.

Rotating disturbances can be observed already at a mass flow rate greater than the stall inception point and appear as a regular modulation of the flow field prior to surge. This disturbance does not induce a significant flow blockage in the concerned rotor contrary to the rotating stall. They have been sometimes reported as high-frequency rotating stall [5] or pressure waves [6], with cells numbers and rotation speed higher than the ones observed with rotating stall. 


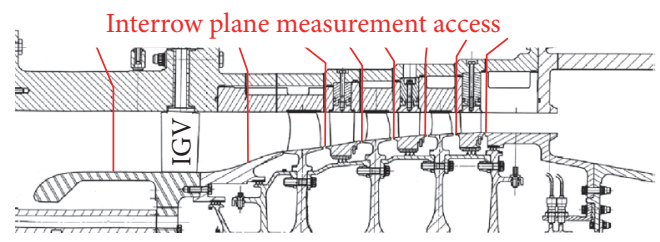

FIgURE 1: Meridian view of CREATE and measurement planes.

A certain controversy called rotating instability (RI) could be understood as a subtype of the rotating disturbances. The RI induces a characteristic frequency bump (or rake) in a pressure spectrum compared to a single peak for the rotating disturbances. The source mechanism of the RI appears to be closely related to the spike formation as demonstrated by Inoue et al. [7] and Yamada et al. [8]. The RI occurs mostly in low-speed compressors and with large rotor tip gaps. A flow separation has to occur at the leading edge of usually a rotor blade, causing a probable leading edge vortex. The flow separation can also be provoked by a corner separation in a case without tip gaps as identified by Beselt et al. [9]. What eventually induces the "unstable" behavior, causing the multiple frequencies, has to be identified yet.

Firstly, the high-speed multistage compressor test case and the experimental methods will be presented. Then, two types of instabilities will be discussed: spike and rotating instability. The high-frequency measurements allow a characterization of the abrupt spike type stall inception at nominal shaft speed. Furthermore, this work will present original results about the periodic behavior of a rotating instability at part shaft speed, contrary to what would be expected from the naming in literature.

\section{Test Case (CREATE)}

For this work, the research compressor CREATE (Compresseur de Recherche pour l'Etude des effets Aérodynamiques et TEchnologiques) is investigated in the laboratory of fluid mechanics and acoustics (LMFA) at Ecole Centrale de Lyon, France. The geometry and rotation speed of the 3.5stage high-speed axial research compressor are representative of high-pressure compressor median rear blocks of a modern turbojet engine, designed by Safran Aircraft Engines.

The compressor and the measurement planes are presented in Figure 1. The rotor shaft is driven at a design speed of $11543 \mathrm{rpm}$, whereby the flow is slightly transonic in the first stage and fully subsonic in the last two stages. More characteristics of CREATE are given in Table 1. The spatial circumferential periodicity of the 3.5 stages is reduced to $2 \pi / 16$ by choosing all numbers of blades as a multiple of 16 , as stated in Table 2. Consequently one temporal period corresponds to $1 / 16$ th of a rotor revolution. A profound knowledge-base has been acquired with CREATE for numerical and experimental methods aiming at flow field investigations in the high-speed multistage compressor environment [10-13]. Standard tip gap sizes are implemented compared to increased tip gaps in rotors 2 and 3 in the previous version of CREATE.
TABLE 1: Characteristics of CREATE at design point.

\begin{tabular}{lc}
\hline Casing diameter & $0.52 \mathrm{~m}$ \\
Core speed & $11543 \mathrm{rpm}$ \\
Rotor 1 tip speed & $313 \mathrm{~m} / \mathrm{s}$ \\
Rotor 1 tip inlet relative Mach number & 0.92 \\
\hline
\end{tabular}

TABle 2: Number of blades of CREATE.

\begin{tabular}{lccccccc}
\hline Row & IGV & R1 & S1 & R2 & S2 & R3 & S3 \\
\hline $\begin{array}{l}\text { Number of } \\
\text { blades per row } \\
(2 \pi / 16)\end{array}$ & 2 & 4 & 7 & 5 & 7 & 5 & 7 \\
\hline
\end{tabular}

TABLE 3: Relative measurement uncertainties for high frequency static pressure measurements estimated for CREATE by [14].

\begin{tabular}{lcc}
\hline & Weak gradient zones & Strong gradient zones \\
\hline Rotor 1 & $0.47 \%$ & $3.3 \%$ \\
Rotor 2 & $0.51 \%$ & $3.0 \%$ \\
Rotor 3 & $0.60 \%$ & $3.0 \%$ \\
\hline
\end{tabular}

\section{Experimental Methods}

The main characteristics of the high-frequency casing pressure measurements are summarized hereinafter. Furthermore, global performance measurements are conducted but not described in more detail here. Ottavy et al. [10] state more details about this test rig and give an exhaustive introduction of the experimental methods, whereas only a brief summary is given hereinafter.

3.1. High-Frequency Wall Static Pressure Measurements. High-frequency wall static pressure measurements have been carried out for a general description of the flow field and the study of the onset of instabilities near surge and the surge inception. For capturing all the unsteady features of the flow, the wall static pressure measurements have been acquired simultaneously with a frequency of $500 \mathrm{kHz}$ using 48 sensors (Kulite: XTE-190). Six probes can be installed per interrow plane and 12 probes per rotor tip. The sensors, used without their protective grid, have a correct frequency-response up to about $160 \mathrm{kHz}$, where the BPFs of rotors 2 and 3 correspond to $15 \mathrm{kHz}$. More details about the high-frequency-response acquisition system are stated in the works of Gourdain et al. [11] and Courtiade [14], and the relative measurement uncertainty is given in Table 3 .

3.2. Data Treatment Methods. The data treatment is done consistently in this work and defined hereinafter. The mass flow rate, isentropic efficiency, and pressure ratio are normalized by their respective maximum values or given as difference. Entropy, temperature, and pressure are normalized by their overall time-mean rise in the compressor according to (1). The time axis might be normalized by the rotating 
frequency of the shaft. The nondimensional data is labeled "normalized" (or "norm.")

$$
X_{\text {norm }}=X_{\text {mes }} \times \frac{1}{\overline{X_{\text {outlet }}}-\overline{X_{\text {inlet }}}} .
$$

Static variables are arithmetically averaged in space, whereas convected variables $\left(X_{c}\right)$ are weight-averaged by the axial velocity $\left(V_{x_{i}}\right)$ according to

$$
\overline{X_{c}}=\frac{1}{N \cdot \bar{V}_{x}} \cdot \sum_{i=0}^{N-1} X_{i} \cdot V_{x_{i}}
$$

Temporal averages are performed as arithmetic averages.

In this work, rotating frequencies of flow structures are obtained with the help of cross-correlations between the signals of probes (e.g., signal 1 and signal 2) located at identical axial positions but different circumferential positions. The cross-correlation allows the estimation of the time lag between the passing of a flow structure in front of probe 1 and that in front of probe 2 . The time lag is estimated between the maximum of the autocorrelation of signal 1 and the maximum of the cross-correlation between signals 1 and 2 .

Knowing the circumferential distance between the probes ( $\Delta \theta_{12}$ in radians) and the time lag ( $\Delta t$ in seconds), a rotating frequency $\left(\omega_{\text {flow structure }}\right)$ can be calculated according to

$$
\omega_{\text {flow structure }}=\frac{1}{2 \pi} \cdot \frac{\Delta \theta_{\text {probes }}}{\Delta t} .
$$

\section{Stall Inception in the Compressor CREATE}

The stall inception type is a function of the rotor speed in this high-speed compressor. In this work it is therefore possible to present observations on rotating instabilities and spikes.

4.1. Global Overview. The global total pressure ratios at $80 \%, 90 \%$, and $100 \%$ shaft rotation speed are presented in Figure 2 and give an overview of identified instabilities in this compressor. The pressure rise distributions reach a rather flat part towards the low mass flow rate before the system falls into surge (see "approximated surge line"). The often called "peak" of the pressure rise distribution is not exceeded here at any rotation speed. The measurements allow the detection of a spike type stall inception at $100 \%$ shaft speed and a rotating instability (RI) type stall inception at part shaft speed. This work will present observations concerning these two instabilities with detailed measurement data at $80 \%$ (representative of the part speed flow field) and 100\% shaft rotation speed.

In this compressor and as usual in a well matched multistage compressor [1], the instability and stall inception occurs in rotor 1 . The general characteristics of the instability onset are described with help of Figure 3 for $80 \%$ shaft speed on the left and $100 \%$ shaft speed on the right. Six signals are presented per speed. They are obtained from the highfrequency casing pressure probes that are positioned around the circumference at a plane just upstream of rotor 1. For these surge inception measurements, the outlet throttle valve

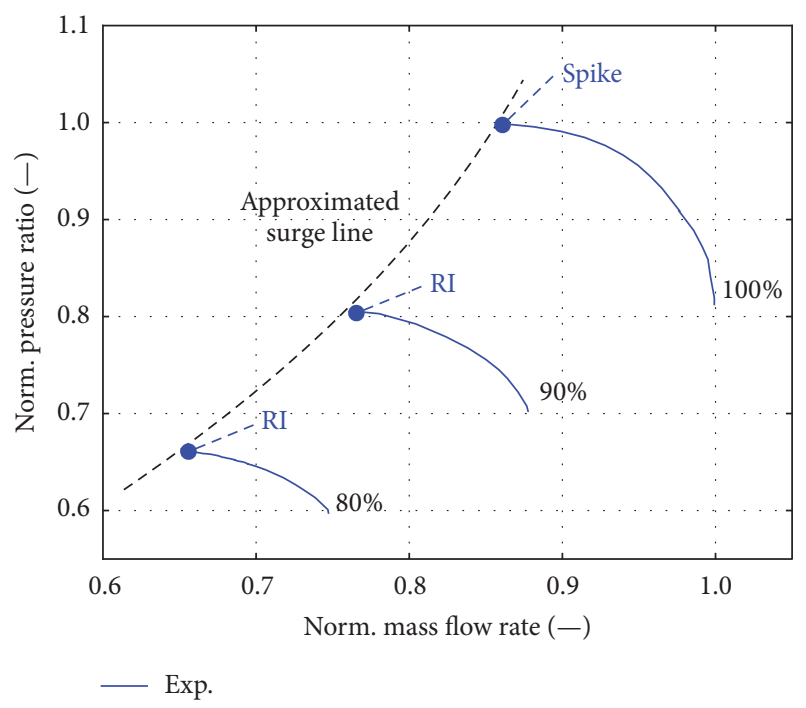

Figure 2: Experimental results for total pressure ratio at part and nominal rotation speeds.

is closed continuously and very slowly from a stable operating point, giving quasi-steady operating conditions and avoiding the generation of "steps" in the pressure signals when the throttle is closed step by step. The signals are low-pass-filtered below the BPF and they are shown for 23 rotor revolutions.

At both shaft speeds, a single rotating stall cell forms between rotations 14 and 18 . The circumferential extension of the cell is growing rapidly during two rotations while the cell's $L E$ is rotating at $0.6 \Omega$ (estimated with cross-correlations according to (3)). The compressor falls abruptly into surge between revolutions 18 and 20 .

At $80 \%$ shaft speed, the instability is present in hundreds of rotations prior to the rotating stall cell (quantified later in Figure 7). It is seen as somewhat of noise in the signals here. The rotating stall cell forms (indicated with the black dashed circle) without any detectable trace of a spikelike flow perturbation in this compressor. The difference between the rotating stall cell and RI signature will be discussed with a wavelet analysis later on.

At $100 \%$ shaft speed, the typical increase and decrease related to a spike type perturbation are found [4]. The increase and decrease of the static pressure extend each over four rotor blade passing instances (not detailed here). At the first detection, the rotating speed of the spike is estimated to be $0.9086 \Omega$ with the help of cross-correlations between the six signals, applying (3). The spike structure evolves within less than 2 rotor revolutions into a single rotating stall cell, which is forming at revolution 16 . The whole stall inception process is abrupt at $100 \%$ shaft speed and takes less than 20 rotor revolutions in any measured case and a stall warning system could not react in this short span of time.

At all investigated shaft speeds, temporal mode 1 (normalized by the shaft rotating frequency) is present in the flow field in rotor 1 . At $80 \%$, this mode causes a modulation of the rotating instability and can be found as a wavelike modulation of the signals in Figure 3(a). At 100\% shaft speed, mode 1 


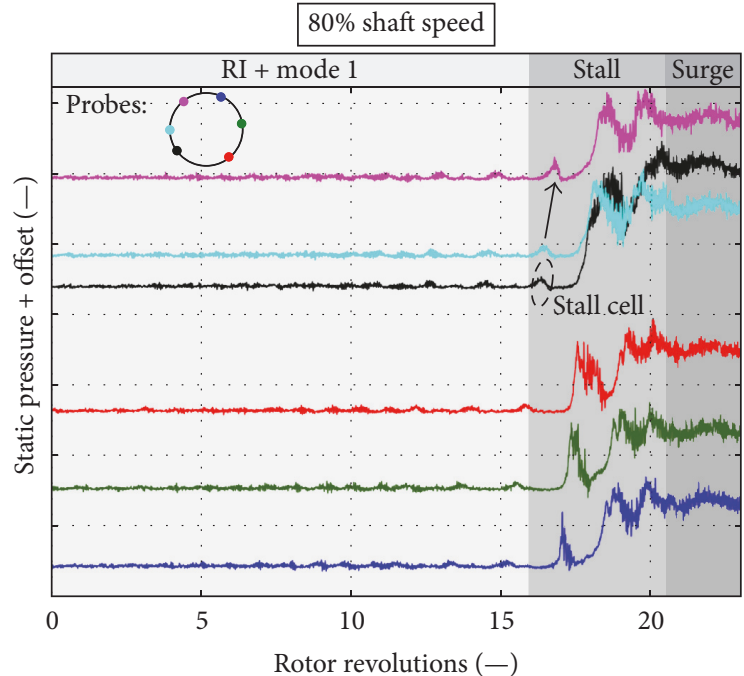

(a)

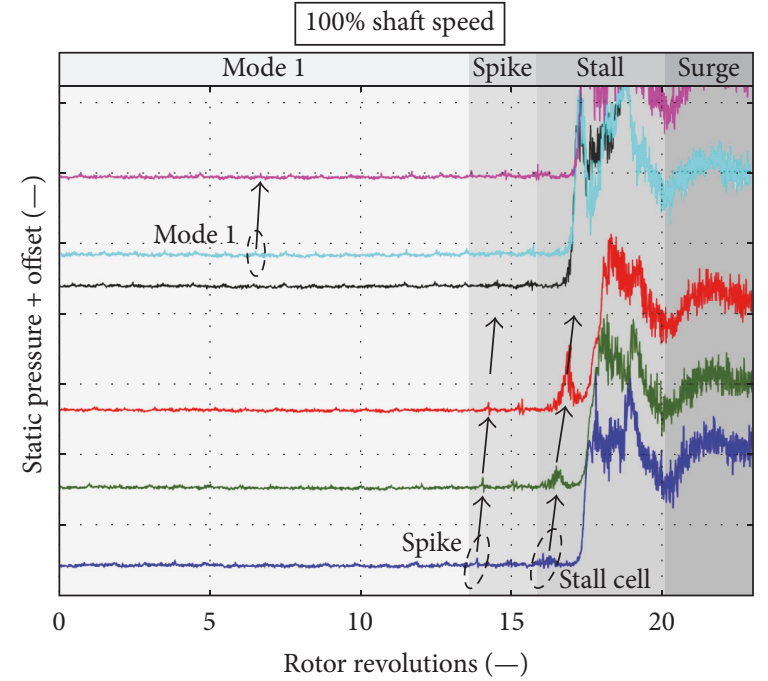

(b)

FIGURE 3: Static pressure signals (low-pass filtered below BPF) of six probes around the circumference upstream of the rotor 1 LE during stall inception at $80 \%$ (a) and $100 \%$ (b) shaft speed with an identical scale.

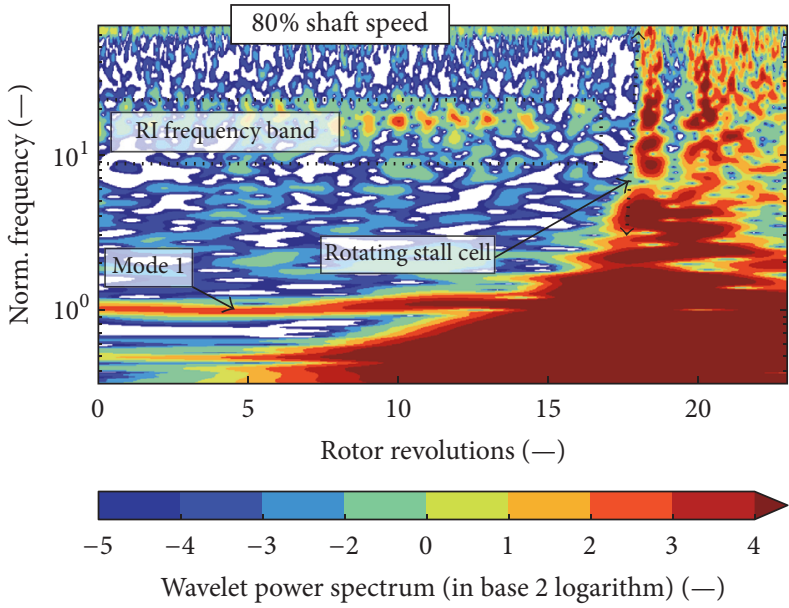

(a)

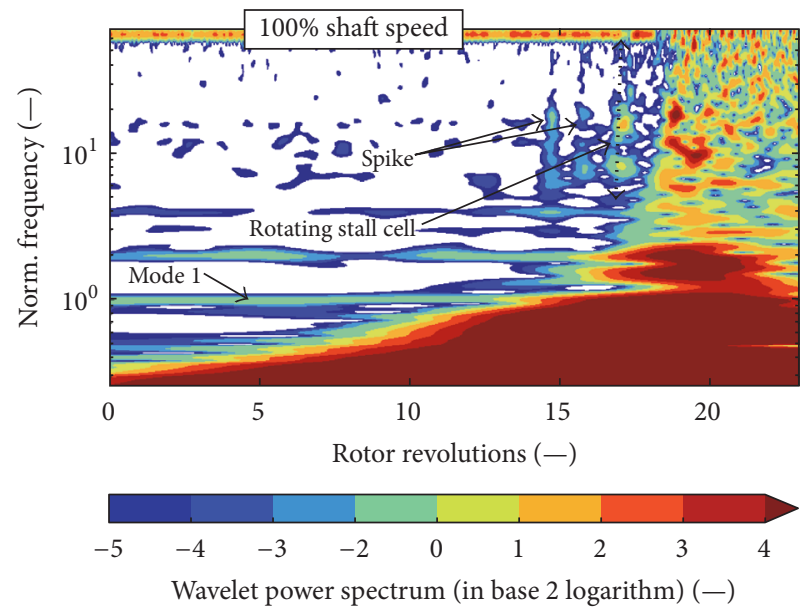

(b)

FIgURE 4: Wavelet power spectra for the green signals (2nd circ. pos. from the bottom) in Figure 3 for $80 \%$ (a) and $100 \%$ (b).

is visibly better because no instability is present in the flow field. The rotation speed of this mode corresponds to the rotation speed of the shaft. It might be therefore the signature of a geometrical default in the rotor. This default might be found in about 4-8 blades (temporal extension of pressure peaks) with a different tip gap than the surrounding blades but further tip gap measurements are necessary to support this hypothesis. It might be the geometrical trigger for the onset of the spike inception. Weichert and Day [15] found that, in $90 \%$ of the investigated stall inception events, the spike perturbation would form in the same rotor passage due to a geometrical default.

Wavelet spectra shall clarify the timeline of the formation of the instability structures during the stall inception. Figure 4 shows the wavelet power spectra computed on the green signal (2nd signal from the bottom) in Figure 3. The wavelet spectra are obtained using the tools of Torrence and Compo [16] with a Morlet wavelet, which has been proven useful for turbomachinery applications, for example, by Lin et al. [17]. The wavelet analysis is conducted in each case with an input signal normalized by the standard deviation computed on the first half of the signal. The vertical axis traces the normalized frequency (by the shaft rotating frequency) and the horizontal axis the rotor revolutions, which correspond to the ones presented in Figure 3.

At $80 \%$ speed, the RI is seen as a wide frequency band with elevated power. The origin of these frequencies will be discussed later on in this work. The BPF is located at the upper limit of the spectrum. It corresponds to the normalized frequency 64 whereas the RI frequency band can be seen 

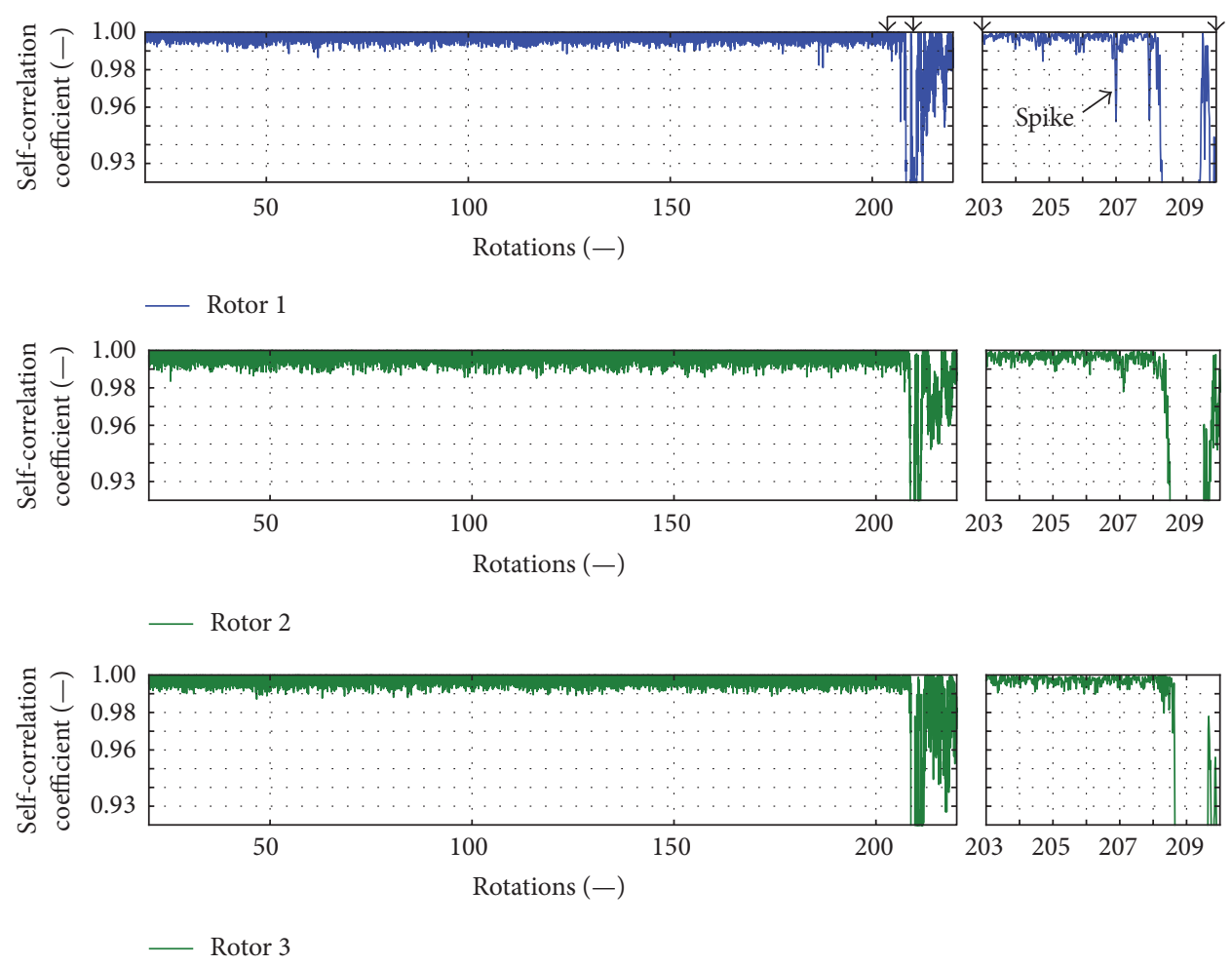

FIGURE 5: Disturbance detection by “self-correlation" of casing pressure signals at LE of rotors 1 to 3 at $100 \% \Omega$.

around 18 . The BPF is not disturbed by the rotating instability. The rotating stall cell appears as a vertical trace in the wavelet spectrum. Low frequency content related to the rotating stall and surge causes the zone of high power (red). The absence of the interblade pressure gradient due to the detached flow (rotating stall cell) is found as an interruption of the BPF trace in the wavelet spectrum. Surge is eventually seen as a chaotic spectrum without a clear frequency content starting from about rotor revolution 19.

At $100 \%$ shaft speed, mode 1 is present as well (Figure 4(b)) up to the rotating stall inception. Tracing of mode 1 is no longer possible once the low frequency content arises (large white zone) and a clear link between mode 1 and the spike is therefore not possible. The spike is seen at normalized frequency 16 . That corresponds to the inverse of the temporal extension. With 64 rotor blades, the temporal extension corresponds thus to $25 \%$ of the rotor blades passing in time. Recent research work demonstrates a vortexlike structure as the initial form of the spike, for example, the work of Pullan et al. [4]. This present arrangement of measurement probes does not detect this vortexlike structure with less than one pitch extension. The spike structure might grow too rapidly circumferentially in between the measurement probe locations.

The flow perturbation is understood as a rotating stall and no longer spike or RI, when the BPF is disturbed because of the possible absence of the interblade pressure gradient. This frontier is indicated with a dashed line (with arrows at both ends) for both shaft rotation speeds.
A fine spike detection method and the origin of the RI frequency band are discussed in the following parts of this paper.

4.2. Spike Detection Method. The temporal and spatial locations of the stall inception are identified with an analysis of the casing pressure signals above the rotors (close to the LE) during more than 200 rotor revolutions prior to any surge inception. One example is presented for the spike type stall inception at $100 \%$ shaft speed in Figure 5. For this detection method, the signals are cut in segments representing each temporal period $(2 \pi / 16 \Omega)$ and are low-pass-filtered below the blade passing frequency at $7 \mathrm{kHz}$, allowing the detection of small (compared to BPF) stall inception related disturbances. A cross-correlation is calculated between each segment and the corresponding one a revolution earlier ("self-correlation"). Normalized by the autocorrelation, a correlation coefficient of 1 represents a perfect match between two signals. The maxima of the cross-correlations per temporal period are eventually plotted and give a fine measure for meaningful changes in the flow field. This stall precursor detection method resembles the one proposed by Dhingra et al. [18]. A spike would decrease the maximum correlation coefficient. Please note that the rotor revolution numbers in Figure 5 are not related to the one seen in Figure 5 earlier.

Globally, the unsteadiness increases in flow direction. This is seen as increasing background noise or band of fluctuations between 0.99 and 1 . The surge inception occurs between revolutions 208 and 209 and is found as drop of the coefficient below values of 0.925 . In this example, a 


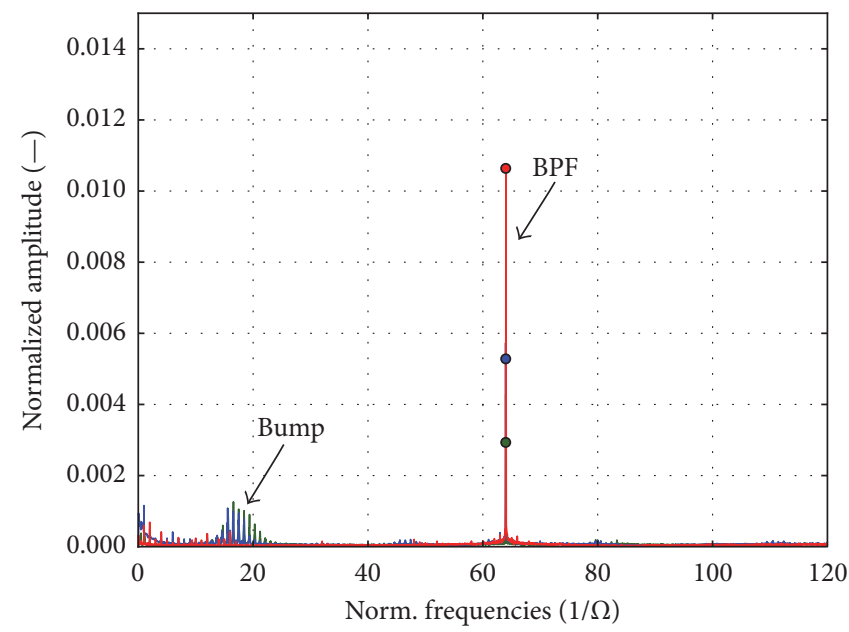

$-\quad 80 \% \Omega$
$-\quad 90 \% \Omega$
$-\quad 100 \% \Omega$

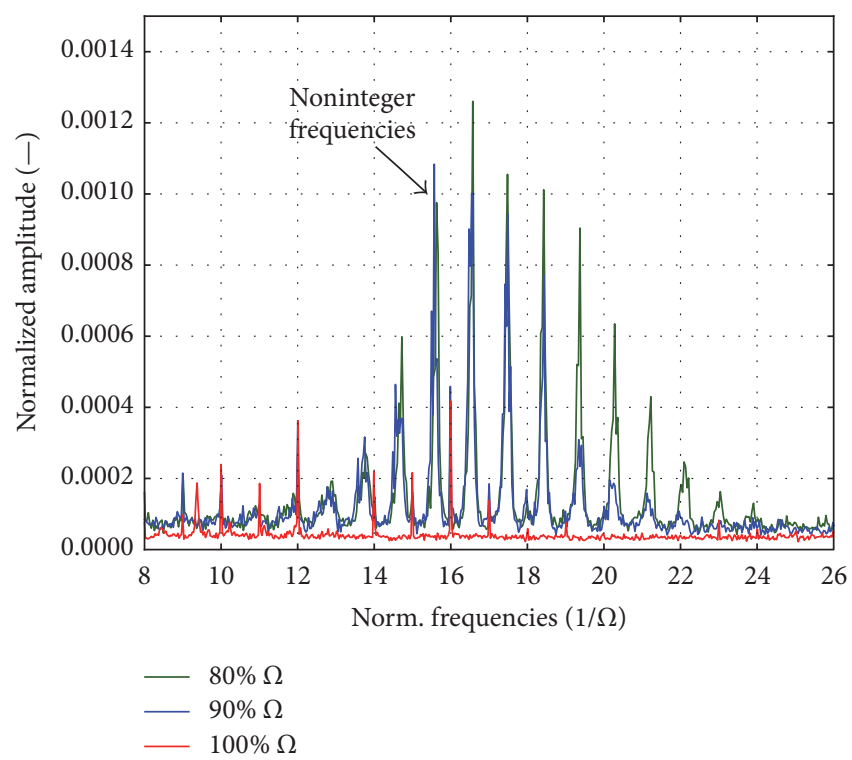

(b)

FIGURE 6: Frequency spectra of a casing pressure probe close to the rotor $\sim 1$ LE in comparison of three shaft rotation speeds $(80 \% \Omega, 90 \% \Omega$, and $100 \% \Omega$ ), "full" spectrum (a), and zoom on frequency bump (b).

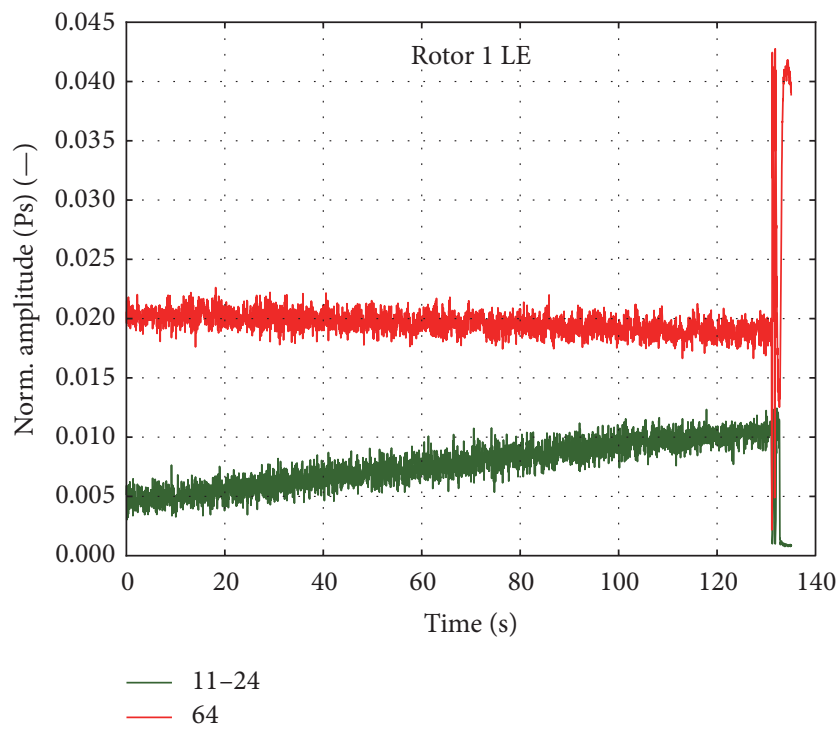

FIGURE 7: Temporal evolution of rotating instability modes (11 to 24) and rotor blade passing frequency during surge inception measurement.

disturbance appears about 20 revolutions prior to the surge inception in rotor 1 (understood as "predisturbance"). It causes the coefficient to drop to a value outside of the noise band. With the instrumentation setup, this is not always observed before surge inception in this compressor. In all surge inception measurements though, the "last" disturbance prior to surge occurs first in rotor 1 . This can be seen in the zoom in Figure 5 on the right at revolution 207. During the same revolution, a disturbance is also found in rotor 2 . In none of the measurements, rotor 2 shows the disturbance prior to the one in rotor 1. Furthermore, the predisturbances occur only in rotor 1 and never in rotor 2 or 3 . A disturbance arises always last in rotor 3 , only as a consequence of the disturbances upstream. In conclusion, disturbances leading to the stall inception of the compressor occur in rotor 1.

This method was also applied to measurements at part shaft speed but a unique perturbation such as the spike was not detected (not shown here). The observations on the RI and the stall inception with the RI present in the flow field will be presented hereinafter.

4.3. Rotating Instability (RI). For an operating point close to the stall limit, frequency spectra are obtained from signals of a high-frequency casing pressure probe axially located close to rotor 1 leading edge and presented for three shaft speeds $(80 \% \Omega, 90 \% \Omega$, and $100 \% \Omega$ ) in Figure 6. The input signals have a length corresponding to about 400 rotor revolutions, and the spectra are integrated over bands of $6 \mathrm{~Hz} / \Omega$ to reduce the noise. Always when approaching the stall limit at part speeds $(80 \% \Omega$ and $90 \% \Omega$ ) with the CREATE compressor, an increase of several amplitudes (forming a "bump") is observed in these frequency spectra at about $30 \%$ of the dimensionless blade passing frequency (12 to 24 compared to 64). The maximum amplitude of the bump reaches about $12 \%$ of the BPF of the rotor 1 . That is also the case in the measurements for a previous version of the compressor at part speed but has not been investigated before. These frequencies do not arise at $95 \% \Omega$ in the previous compressor version. Thus the switch from spike type stall inception to a type with multiple frequencies happens probably between $90 \% \Omega$ and $95 \% \Omega$. The available measurement data does not allow linking this switch to a change in the flow field.

The multiple peaks are characteristic of rotating instabilities as commonly reported in literature. The discrete peaks 
are found at about the same normalized frequencies comparing multiple measurements for the two part shaft speeds presented in this paper. The RI peaks arise at nonintegers of the shaft speed. This is different from the $100 \%$ shaft speed, where peaks are found in the same frequency range but are harmonics of the shaft rotation speed, or correspond to harmonic 16 which is linked to the compressor periodicity. At $100 \%$ shaft speed, a noninteger exception is the normalized frequency of about 9.3. It is not related to the RI but probably related to an acoustic phenomenon in the downstream rotors, as referred to in the work of Courtiade and Ottavy [6].

The frequency gap between the RI peaks is constant and is a characteristic of RI. This link between the peaks and the rotating frequency was also identified by Kameier and Neise [19]. It corresponds to the rotating frequency of the RI. In the present case, the rotating speed $\left(\omega_{\mathrm{RI}}\right)$ has been calculated from the cross-correlations between signals obtained at different circumferential positions just upstream of rotor 1, applying (3). It leads to $\omega_{\mathrm{RI}}=0.925 \Omega$, which perfectly fits the frequency gaps between the peaks of the RI bump.

Rotating frequencies of $0.5 \Omega$ to $0.65 \Omega$ have been reported in several works on RI $([2,20-22])$ and $0.7 \Omega$ was reported by Inoue et al. [7]. Note that among these references the works of Baumgartner et al. [20] and VignauTuquet and Girardeau [22] were conducted on high-pressure compressors. Also a rotation speed of $0.9 \Omega$ has been reported by Zhang et al. [23] in a numerical work on a turbine working locally as a compressor at low mass flow rate. In the present case, $\omega_{\mathrm{RI}}=0.925 \Omega$ appears high but not out of range of what has been reported in literature. The maximum amplitude is found close to the rotor $1 \mathrm{LE}$ and there is no trace of the instability in rotors 2 and 3 (not detailed here). Likewise, Mailach et al. [2] reported the maximum RI amplitude in the first $30 \%$ of rotor blade chord. Furthermore we know from their work (and others) that the RI trace is usually limited to $10 \%$ of span towards the casing.

Figure 7 presents the RI bump's amplitude evolution over hundreds of rotations towards surge inception. The temporal evolutions of the RI (integrated over the normalized frequencies from 11 to 24) and the rotor 1 BPF are presented based on the casing pressure signal from a probe positioned close to the rotor $1 \mathrm{LE}$. The temporal evolution is obtained from windowed Fourier transforms using signals with a length of three rotor revolutions per window and an overlap of 1.5 revolutions. The measurements start at a loaded stable operating point and the outlet throttle valve is closed very slowly giving quasi-steady operating conditions. The compressor falls into stall and surge after about 131 seconds from the beginning of the presented acquisition. During the valve closing, the BPF decreases in amplitude by less than $10 \%$ but the integrated amplitude of the RI doubles. The RI amplitude reaches a critical level (close to stall) when it surpasses half of the BPF amplitude in this compressor configuration. This information could be fed into a stall warning system. Eventually, the RI is evolving into rotating stall without a detectable spike type stall inception as shown in Figure 3.

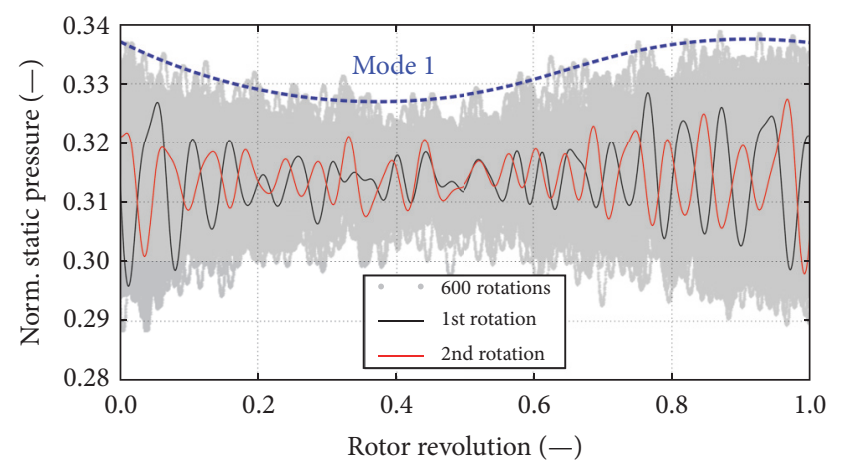

FIgURE 8: Casing pressure signal of 600 rotor revolutions stacked and superposed on two example revolutions (low-pass filtered at $5 \mathrm{kHz}$, below $\mathrm{BPF}$ ) at a location above rotor 1 close to the LE.

The main focus in the next section is put on the periodic rotating behavior of the RI in this compressor, contrary to the unstable behavior suggested by the naming "rotating instability."

4.3.1. Variation of Temporal Extension of RI Disturbances. The observations on the temporal extension variations of the RI disturbances will be presented from raw signal plots to a detailed frequency analysis in this section.

Figure 8 shows unsteady casing pressure signals acquired with a measurement probe located close to the LE of rotor 1 at the casing. The signals are low-pass-filtered below the BPF at $5 \mathrm{kHz}$. An example of two successive rotor revolutions is plotted in red and black. The oscillations in those signals correspond to RI passing in front of the probe. The grey envelope is obtained in superimposed time trace of the pressure signals over 600 rotor revolutions. It reveals temporal mode 1 over one rotor revolution. The minimum modulation is found at about 0.4 rotor revolutions and the maximum modulation at the beginning or ending of the rotor revolutions. The amplitude modulation is in the order of magnitude of the RI induced fluctuations. With the RI present, the amplitude modulation might present the influence of the compressor on the RI. One could imagine that, once per rotor revolution, rotor blades with different tip gaps than the average pass by the measurement probe and modulate the RI amplitude. This is a hypothesis but could not be verified because timeresolved tip gap measurements were not available.

Figure 9 presents also the two previous successive pressure signals, but with a time axis now equal to the RI revolution time period $\left(t_{\mathrm{RI}}=1 / \omega_{R}=1 / 0.925\right.$ rotor rev.). Those two pressure signals are well in phase. This could be shown for any two arbitrary successive signals. It reflects the temporal periodicity of the RIs (related to the rotating frequency $\omega_{\mathrm{RI}}$ ) over the RI revolution time period. Furthermore, a regular spaced cosine is also plotted in the figure as a reference (black dashed line). The peaks of the two pressure signals are aligned only very few times with the reference cosine. That implies a temporal extension variation of the RI disturbances out of the perspective of the fixed probe in the casing. This temporal extension variation appears periodic because of the 


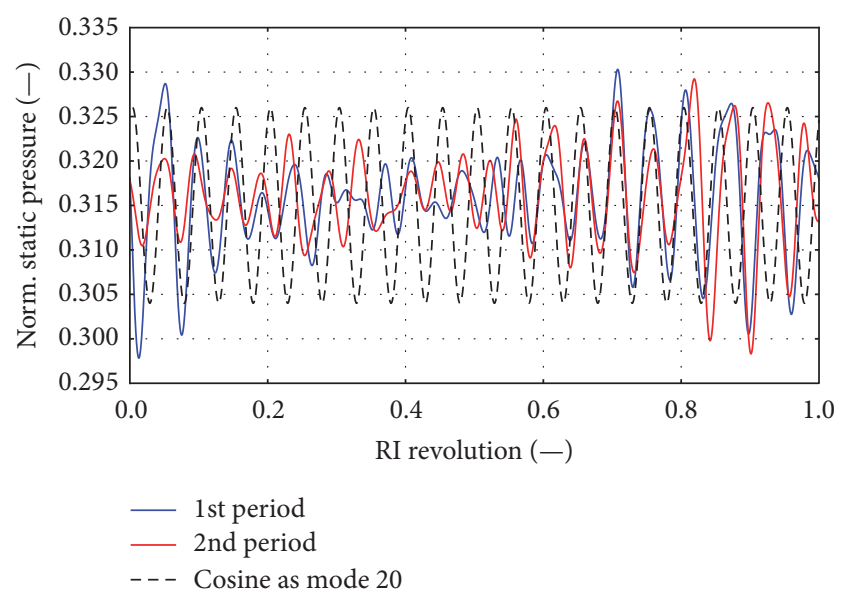

FIGURE 9: Two successive RI revolutions of the rotating instability in the casing pressure signal from above the rotor $1 \mathrm{LE}$ (low-pass filtered at $5 \mathrm{kHz}$, below BPF, colored lines), and cosine as reference (black dashed line).

fairly good match between the two periods. Additionally, the effect of the previously demonstrated amplitude modulation (AM), associated with mode 1 in Figure 8, is visible here. The AM causes peaks of different amplitudes between two RI revolutions ("red" versus "blue") at a given time point of a RI revolution. That can be explained by the fact that the AM is not periodic to a revolution of the RI but to a rotor revolution.

In conclusion, the pressure signals present fluctuations with nonconstant periods which are in phase over a time corresponding to one RI revolution, but an amplitude modulation of the RI is imposed by the rotor periodicity.

Hereafter, the variation of the temporal extension of the $\mathrm{RI}$ induced fluctuations is evaluated with a wavelet analysis.

Figure 10 shows the casing pressure signal (a) low-passfiltered at $7 \mathrm{kHz}$ (below BPF). Counting the RI induced peaks in the signal does not yield a constant number per rotor revolution. The short signal length of three rotor revolutions might give another impression because of the temporal periodicity being very close to one shaft rotation $\left(1 / \omega_{R}=\right.$ $1 / 0.925 \mathrm{rev} .=1.081 \mathrm{rev}$.).

At the bottom of the same figure, the wavelet power spectrum is shown with a zoom on the rotating instability frequencies. The variation of the temporal extension of one RI disturbance is seen as a modulation in the wavelet spectrum. A high frequency is related to a narrow peak (short temporal extension) in the low-pass-filtered signal, and vice versa for a low frequency. The temporal evolution of the "frequency with the maximum wavelet power" can be extracted as a signal, which is sketched with the black solid line.

This "frequency with the maximum wavelet power" signal is presented for 10 rotations in Figure 11(a). Faulty peaks can be explained by the limited temporal resolution of the wavelet spectrum. With Fourier transforms of this extracted signal, the frequency spectrum is computed and shown in Figure 11(b). The main frequencies constituting this signal are the rotating frequency of the rotating instability $\left(\omega_{\mathrm{RI}}=\right.$ $0.925 \Omega$ ) and its harmonics.

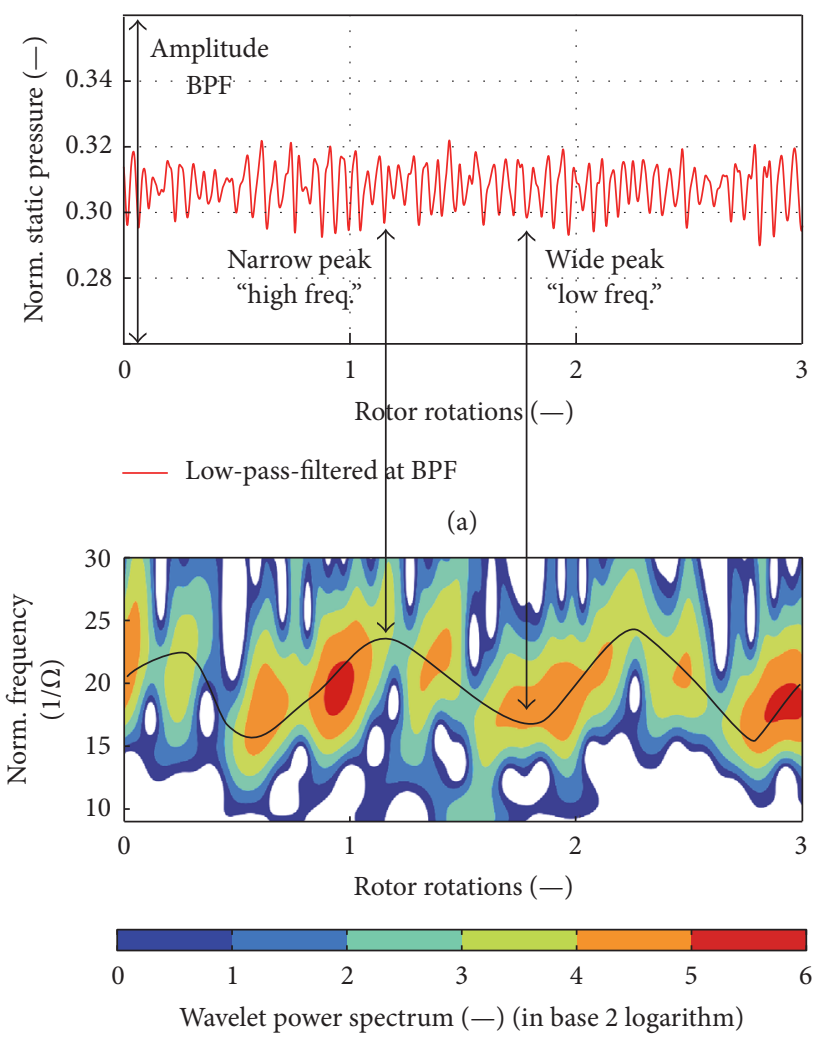

(b)

FIGURE 10: Rotating instability characterization with casing pressure signals over three rotor revolutions (a) and wavelet power spectrum (b).

This result allows the interpretation that the rotation of the disturbance relative to the blade row seems to cause the periodic modulation of the disturbance over the circumference. Consequently, the temporal period of the modulation corresponds to $1 / \omega_{\mathrm{RI}}=1.081$ rotor revolutions. In other words, one RI revolution corresponds to 1.081 rotor revolutions. Counting the peaks passing over 600 RI revolutions leads to a mean number of 20.097 peaks per RI revolution, with a standard deviation of 1.02 peaks. Note that RI revolutions with 21 peaks are followed immediately by RI revolutions with 19 peaks, which explains the standard deviation. This shows that there is no change in the number of peaks or rotation speed of the instability over hundreds of RI revolutions up to rotating stall inception.

4.3.2. Discussion. The result of a classical RSI would be a regular spaced (in time and space) lobed structure according to Tyler and Sofrin [24] and induce a single peak in the frequency spectra of a pressure signal. For a multistage compressor, Courtiade et al. [25] demonstrated that the amplitude of the mode could change with the time, but not its frequency. The RI is not a classical RSI because it is found as an irregular spaced lobed structure in time. That means its structure is not imposed by a blade row with constant blade pitches. The periodic temporal extension variations resemble the result of a classical frequency modulation (FM), which consists of a 


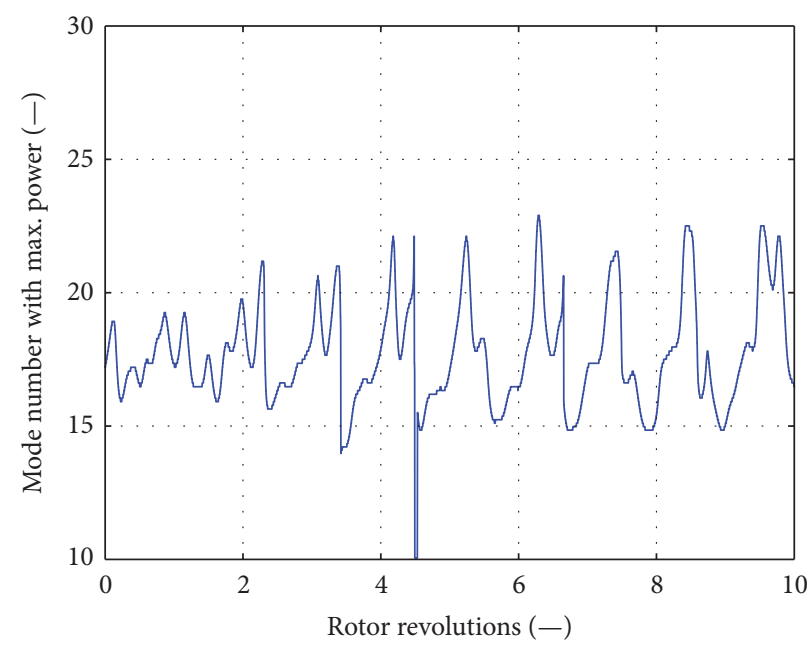

(a)

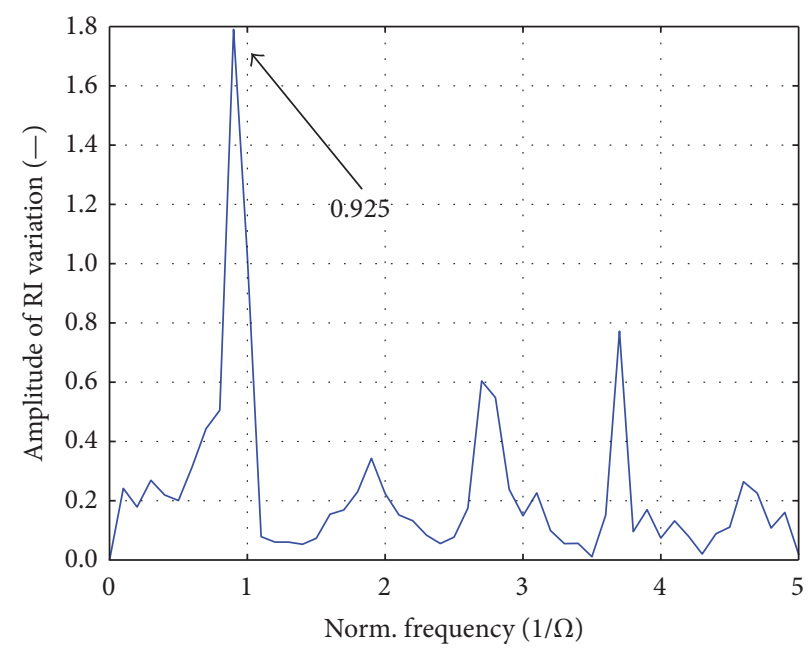

(b)

FIGURE 11: Frequency variation of rotating instability over time: temporal evolution (a); frequency spectrum (b).

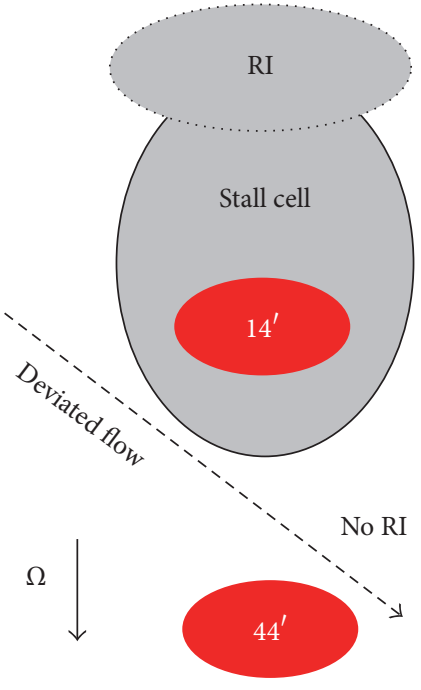

(a)

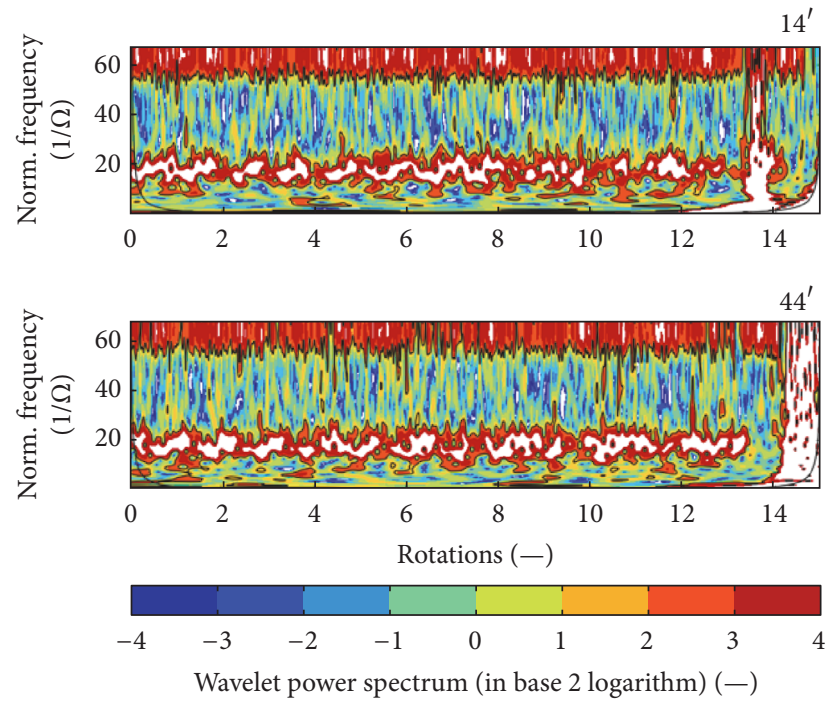

(b)

FIGURE 12: Rotating instability trace in wavelet analysis (b) and sketch (a) based on two signals positioned upstream of rotor 1 at $14^{\prime}$ and $44^{\prime}$ (red ellipse).

high frequency (the carrier signal) and a modulation signal. Furthermore, a FM would also be seen as multiple peaks in a frequency spectrum. In the case of the RI, the carrier frequency is a theoretical unmodulated rotating disturbance with a frequency of $f_{c}=20 \times 0.92 \Omega=18.5 \Omega$. The rotating disturbance might be caused by a separation vortex on the rotor blade suction surface and its interaction with the neighboring blade passages [3] but cannot be resolved with the fairly coarse measured grid (12 synchronized wall pressure probes). The modulation signal is equal to the rotating frequency of the RI with $f_{m}=\omega_{\mathrm{RI}}=0.925 \Omega$ (as found with the wavelet analysis). A relative motion of the disturbance to the blades would be also observed in a compressor cascade, where RI can also occur as shown by Beselt et al. [9].
4.3.3. RI at Stall Inception. We observed in this compressor that once a rotating stall cell is detected (e.g., local vanishing of interblade pressure gradient), the frequency trace of the rotating instability disappears as shown in Figure 12. The signals of two probes (positioned at $14^{\prime}$ and $44^{\prime}$ upstream of rotor 1) are analyzed with wavelet transforms, and the amplitude variations of the normalized frequencies up to the rotor $1 \mathrm{BPF}$ are given in the two power maps. The signals are zoomed in about 13 rotations prior to rotating stall inception. The wavelet transforms are conducted with a temporal resolution which allows the detailed analysis of the amplitude evolution. A wavelet analysis is always a tradeoff between frequency and temporal resolution. Thus the frequency resolution of the BPF is not ideal here and is 
found as a large horizontal band above normalized frequency 60. Again, the rotating instability is found in the band of normalized frequency of 11 to 24 .

The stall inception is seen as vertical stripe of elevated power (white) at rotation 13.5 at the top $\left(14^{\prime}\right)$ and rotations 14 at the bottom $\left(44^{\prime}\right)$. Note that the rotor is turning from probe $1\left(14^{\prime}\right)$ to probe $2\left(44^{\prime}\right)$, and so does the rotating stall cell. Close to the probe at $14^{\prime}$ the rotating stall cell forms, induces a blockage, and causes a diversion of the flow that decreases the loading in this part of the rotor, as introduced by Emmons et al. [26]. As a consequence, the rotating instability is no longer seen in the unloaded sector of the rotor, that is, by the probe at $44^{\prime}$. This behavior is summarized in the sketch in Figure 12(a). The rotating instability disappears thanks to the reorganization of the flow field. This shows the very fast response of the rotating instability to changes in the flow field. The rotating instability does not reappear once the rotating stall cell is established as can be seen after rotation 14 of the signal at $14^{\prime}$.

\section{Conclusion}

This work made use of high-frequency measurements for the study of rotating instability and spike type stall inception in a high-speed compressor.

Widely reported characteristics of rotating instabilities in low-speed compressors could be identified here (e.g., frequency rake and rotation speed) at part speed in this high-speed multistage compressor (CREATE). The highspeed environment and standard tip gap sizes make this an unprecedented test case.

An original new result for the rotating instability is the demonstration of a constant rotation speed $(0.925 \Omega)$ with a constant number of disturbances (20) over a large number of rotating instability revolutions. The variation over time of the disturbance extension was identified to resemble classical frequency modulation (FM), periodic to $1 / 0.925 \Omega$, causing the well-known frequency rake. Additionally, an amplitude modulation (AM) occurs, periodic to a rotor revolution, and marks the modulation of the rotating instability by the compressor system (e.g., geometry defaults). Finally the rotating instability characterized by a bump (frequency rake) in the spectra appears in the present case to be very stable, contrary to the controversy chosen naming.

The modulation of possible rotating separation vortices (forming the rotating instability) needs to be proven with higher spatially resolved measurements. In future collaborative works, the newly identified characteristics of the rotating instability could be verified on existing measurement databases of cases presented in literature.

For nominal compressor speed, a fine spike detection method was applied but the first spikelike perturbations appear usually only up to 5 rotor revolutions prior to surge in this compressor. That demonstrates the abrupt stall onset in the high-speed axial compressor environment. This makes a useful stall warning system impossible. Pressure measurements on the rotor blade surface close to the tip might be necessary for an earlier and finer detection of the spike inception.

\section{Nomenclature}

$\begin{array}{ll}\text { BPF: } & \text { Blade passing frequency } \\ \mathrm{RI}: & \text { Rotating instability } \\ \Omega: & \begin{array}{l}\text { Rotating speed of the compressor } \\ \text { shaft }\end{array} \\ \omega_{\mathrm{RI}}: & \begin{array}{l}\text { Rotating frequency of rotating } \\ \text { instability }\end{array} \\ \mathrm{PE}, \mathrm{L}, \mathrm{NS}: & \text { Peak efficiency, loaded, and near } \\ & \text { surge operating points } \\ \text { Rev:: } & \text { Revolutions } \\ \text { LE: } & \text { Leading edge. }\end{array}$

\section{Conflicts of Interest}

The authors declare that they have no conflicts of interest.

\section{Acknowledgments}

The authors are grateful to Safran Aircraft Engines for supporting the CREATE compressor research program and for granting permission to publish these results. The funding provided via the Consortium Industrie-Recherche en Turbomachines (CIRT) is gratefully acknowledged. The analysis of the measurement data would not have been possible without the high-quality acquisition by the measurement team for the high-speed test rigs at the LMFA, formed of Sébastien Goguey, Gilbert Halter, Pierre Laucher, and Lionel Pierrard. Their help and advice for the work with the experimental data are gratefully acknowledged.

\section{References}

[1] I. J. Day, "Stall, surge, and 75 years of research," Journal of Turbomachinery, vol. 138, no. 1, Article ID 011001, 16 pages, 2015.

[2] R. Mailach, I. Lehmann, and K. Vogeler, "Rotating instabilities in an axial compressor originating from the fluctuating blade tip vortex," Journal of Turbomachinery, vol. 123, no. 3, pp. 453-460, 2000.

[3] M. Inoue, M. Kuroumaru, T. Tanino, S. Yoshida, and M. Furukawa, "Comparative studies on short and long length-scale stall cell propagating in an axial compressor rotor," Journal of Turbomachinery, vol. 123, no. 1, pp. 24-32, 2001.

[4] G. Pullan, A. M. Young, I. J. Day, E. M. Greitzer, and Z. S. Spakovszky, "Origins and structure of spike-type rotating stall," Journal of Turbomachinery, vol. 137, no. 5, Article ID 051007, 11 pages, 2015.

[5] I. J. Day, T. Breuer, J. Escuret, M. Cherrett, and A. Wilson, "Stall inception and the prospects for active control in four highspeed compressors," Journal of Turbomachinery, vol. 121, no. 1, pp. 18-27, 1999.

[6] N. Courtiade and X. Ottavy, "Experimental study of surge precursors in a high-speed multistage compressor," Journal of Turbomachinery, vol. 135, no. 3, Article ID 061018, 9 pages, 2013.

[7] M. Inoue, M. Kuroumaru, S. Yoshida, T. Minami, K. Yamada, and M. Furukawa, "Effect of tip clearance on stall evolution process in a low-speed axial compressor stage," in Proceedings of the ASME Turbo Expo, pp. 385-394, Vienna, Austria, June 2004.

[8] K. Yamada, H. Kikuta, M. Furukawa, S. Gunjishima, and Y. Hara, "Effects of tip clearance on the stall inception process in 
an axial compressor rotor," in Proceedings of the ASME Turbo Expo 2013, San Antonio, Tex, USA, June 2013.

[9] C. Beselt, B. Pardowitz, R. Van Rennings, and P. U. Thamsen, "Influence of the clearance size on rotating instability in an axial compressor stator," in Proceedings of the 10th European Conference on Turbomachinery Fluid dynamics \& Thermodynamicsics, Lappeenranta, Finland, 2013.

[10] X. Ottavy, N. Courtiade, and N. Gourdain, "Experimental and computational methods for flow investigation in high-speed multistage compressor," Journal of Propulsion and Power, vol. 28, no. 6, pp. 1141-1155, 2012.

[11] N. Gourdain, F. Wlassow, and X. Ottavy, "Effect of Tip clearance dimensions and control of unsteady flows in a multi-stage highpressure compressor," Journal of Turbomachinery, vol. 134, no. 5, Article ID 051005, 13 pages, 2012.

[12] J. Schreiber, X. Ottavy, G. N. Boum, S. Aubert, and F. Sicot, "Numerical simulation of the flow field in a high speed multistage compressor-study of the time discretization sensitivity," in Proceedings of the ASME Turbo Expo 2015, Montreal, Canada, June 2015.

[13] J. Schreiber, X. Ottavy, G. N. Boum, and N. Gourdain, "Influence of rotor tip flow field mis-prediction on rotating disturbance near surge in a high speed multistage compressor," in Proceedings of the ASME Turbo Expo 2016, Seoul, South Korea, June 2016.

[14] N. Courtiade, Experimental analysis of the unsteady flow and instabilities in a high-speed multistage compressor [Ph.D. thesis], Ecole centrale de Lyon, Ecully, France, 2012.

[15] S. Weichert and I. Day, "Detailed measurements of spike formation in an axial compressor," Journal of Turbomachinery, vol. 136, no. 5, Article ID 051006, 9 pages, 2013.

[16] C. Torrence and G. P. Compo, "A practical guide to wavelet analysis," Bulletin of the American Meteorological Society, vol. 79, no. 1, pp. 61-78, 1998.

[17] F. Lin, J. Chen, and L. Meilin, "Wavelet analysis of rotor-tip disturbances in an axial-flow compressor," Journal of Propulsion and Power, vol. 20, no. 2, pp. 319-334, 2004.

[18] M. Dhingra, Y. Neumeier, J. V. R. Prasad, and H.-W. Shin, "Stall and surge precursors in axial compressors," in Proceedings of the 39th AIAA/ASME/SAE/ASEE Joint Propulsion Conference and Exhibit, Huntsville, Ala, USA, July 2003.

[19] F. Kameier and W. Neise, "Experimental study of tip clearance losses and noise in axial turbomachines and their reduction," Journal of Turbomachinery, vol. 119, no. 3, pp. 460-471, 1997.

[20] M. Baumgartner, F. Kameier, and J. Hourmouziadis, "Nonengine order blade vibration in a high pressure compressor," in Proceedings of the in 12th International Symposium on Airbreathing Engines, Melbourne, Australia, 1995.

[21] J. März, C. Hah, and W. Neise, "An experimental and numerical investigation into the mechanisms of rotating instability," Journal of Turbomachinery, vol. 124, no. 3, pp. 367-374, 2002.

[22] F. Vignau-Tuquet and D. Girardeau, "Aerodynamic rotating vortex instability in a multi-stage axial compressor," in Proceedings of the in 17th International Symposium on Airbreathing Engines, Munich, Germany, 2005.

[23] L. Y. Zhang, L. He, and H. Stüer, "A Numerical investigation of rotating instability in steam turbine last stage," Journal of Turbomachinery, vol. 135, no. 1, Article ID 011009, 2012.

[24] J. M. Tyler and T. G. Sofrin, "Axial flow compressor noise studies," SAE Transactions, vol. 70, pp. 309-332, 1962.
[25] N. Courtiade, X. Ottavy, and N. Gourdain, "Modal decomposition for the analysis of the rotor-stator interactions in multistage compressors," Journal of Thermal Science, vol. 21, no. 3, pp. 276285, 2012.

[26] H. W. Emmons, C. E. Pearson, and H. P. Grant, "Compressor Surge and Stall Propagation," Transaction of the ASME, vol. 77, pp. 455-469, 1955. 


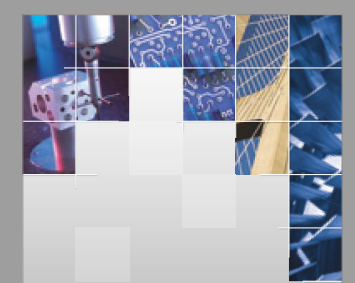

\section{Enfincering}
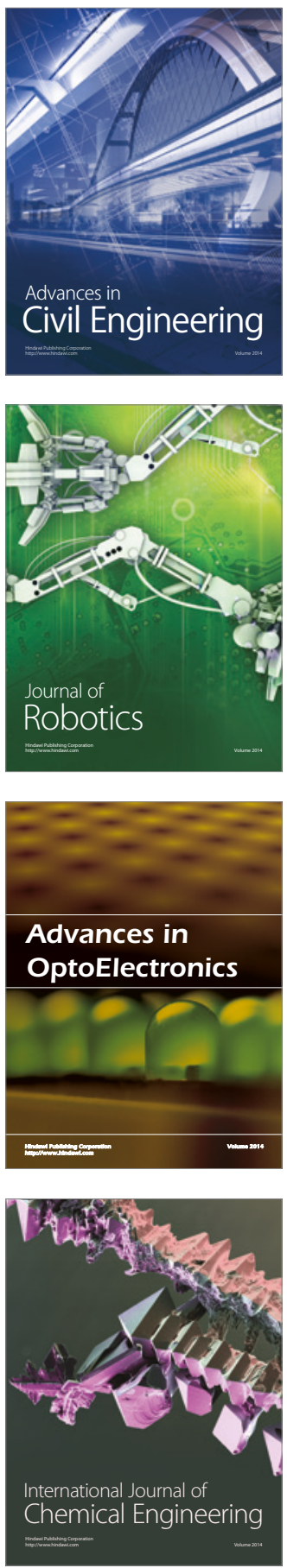

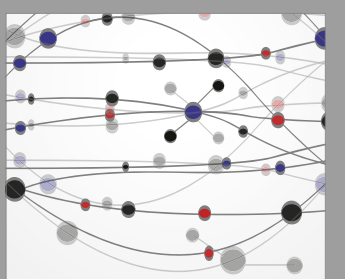

The Scientific World Journal

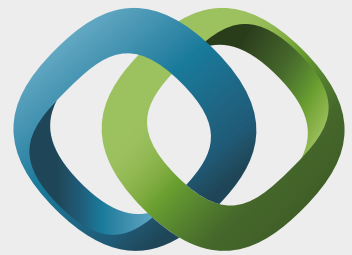

\section{Hindawi}

Submit your manuscripts at

https://www.hindawi.com
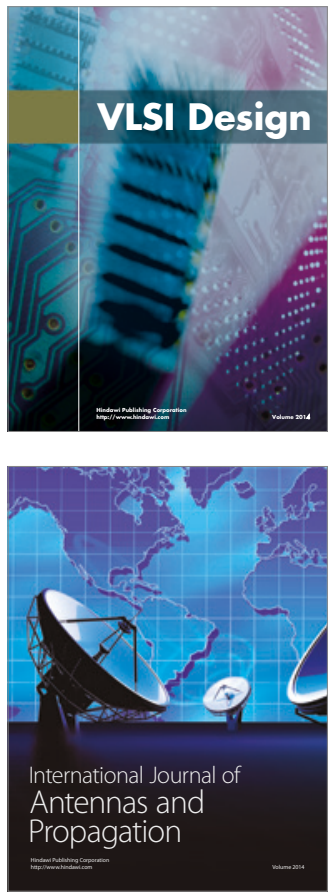

\section{Rotating}

Machinery
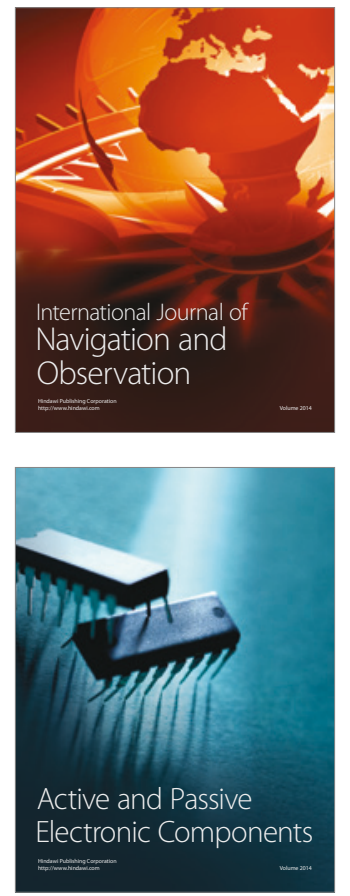
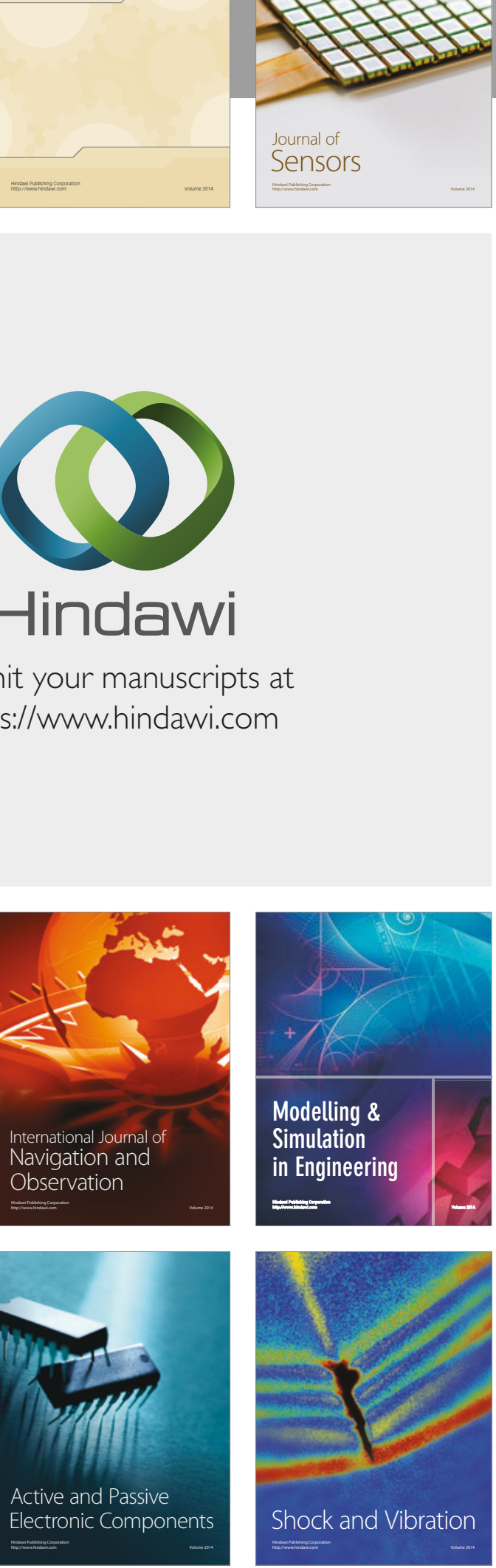
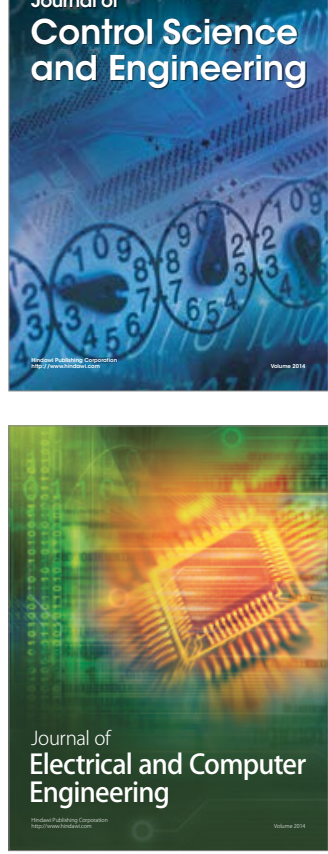

Distributed

Journal of

Control Science

and Engineering
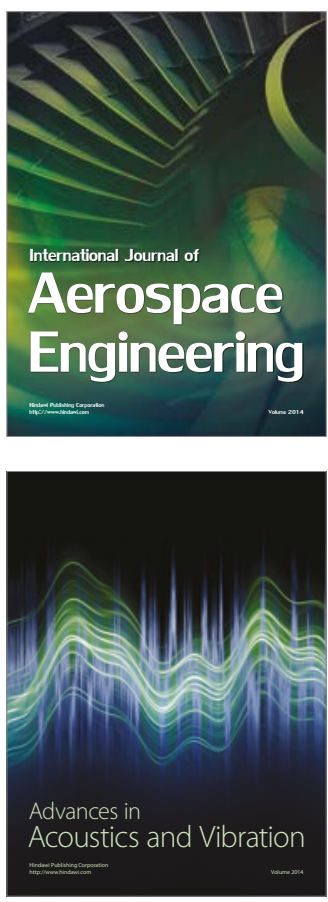

Sensor Networks 